\title{
Complementary mapping techniques to characterize the wood finish of musical instruments
}

\author{
Michela Albano ${ }^{1,2, a}{ }_{(\mathbb{D})}$, Marta Ghirardello ${ }^{1, b}{ }_{(\mathbb{D})}$, Giacomo Fiocco $^{2,3, \mathrm{c}}{ }_{(\mathbb{D})}$, \\ Cristian Manzoni $^{4, \mathrm{~d}}{ }_{\mathbb{D}}$, Marco Malagodi $^{2,5, \mathrm{e}_{\mathbb{D}}}$, Daniela Comelli ${ }^{1, \mathrm{f}}{ }_{\mathbb{D}}$ \\ ${ }^{1}$ Department of Physics, Polytechnic of Milan, Piazza Leonardo da Vinci 32, 20133 Milano, Italy \\ 2 Arvedi Laboratory of Non-Invasive Diagnostics, CISRiC, University of Pavia, Via Bell' Aspa 3, \\ 26100 Cremona, Italy \\ 3 Department of Chemistry, University of Torino, Via Pietro Giuria 5, 10125 Torino, Italy \\ 4 IFN-CNR, Piazza Leonardo da Vinci 32, 20133 Milano, Italy \\ 5 Department of Musicology and Cultural Heritage, University of Pavia, Corso Garibaldi 178, 26100 Cremona, \\ Italy
}

Received: 29 April 2021 / Accepted: 3 October 2021

(C) The Author(s) 2021

\begin{abstract}
The wood finish of historical bowed string musical instruments made in Cremona (Italy) during the seventeenth and eighteenth century is a complex multi-layered coating system, where varnishes and other organic binders are variously mixed with inorganic fillers and pigments. It consists of several layers with reduced thickness (tens of microns or less), hard to be distinguished due to the similarity of the constituent materials. Nevertheless, the identification of chemical and morphological features (layering and boundaries) is strictly necessary to disclose the traditional manufacturing procedures. In this paper, we propose an innovative protocol to fully characterize such a multi-layered coating system by combining hyperspectral photoluminescence (PL) micro-imaging with $\mu$ FTIR-ATR mapping and SEMEDX analysis. The protocol has been employed to study three cross-sectional samples from violins made by Lorenzo Storioni (second half of eighteenth century), whereas a properly reproduced laboratory mock-up was used to set the analytical protocol. The obtained results demonstrate that the combination of these complementary spectroscopy mapping techniques in a high-resolution strategy allows one to clearly identify the morphology of a few microns thin layers, to assess the penetration depth of sizing treatments into the wood and to detect restoration areas.
\end{abstract}

\footnotetext{
a e-mail: michela.albano@polimi.it (corresponding author)

b e-mail: marta.ghirardello@polimi.it

c e-mail: giacomo.fiocco@unipv.it

d e-mail: cristian.manzoni@polimi.it

e e-mail: marco.malagodi@unipv.it

f e-mail: daniela.comelli@polimi.it
} 


\section{Introduction}

Bowed string musical instruments made from the sixteenth to eighteenth centuries in Cremona represent a model for current violin makers. Unfortunately, few written sources are available on the manufacturing procedures. Driven by the rediscovered value of tradition and the musicians' commitment, the investigation and the characterization of historical musical instruments became a matter of study starting from the 1950s of the last century [1].

To transform a bare wood into a ready-to-play instrument, the wood surface is subjected to a series of chemical treatments that turns it into a complex multi-layered coating system in which inorganic micrometric particles (pigments, fillers) are variously mixed with organic binders and varnishes. As described in previous works [2], wood is usually pre-treated with a protein-based layer (e.g., animal glues or caseinates) to seal the wood pores and prepare the surface for the application of the varnish. Besides, an inorganic fraction used as filler is often identified [3-5]. Finally, a varnish layer-commonly made of linseed oil mixed with some natural resins - is spread on the pre-treated wood. Within the mixtures, mineral siccative agents (e.g., lead) and pigments (e.g., iron earth, madder lake) can be included [6-8].

The characterization of such a multi-layered system requires the identification of the chemical composition of each layer as well as the detection of their morphological features, as to say the sequence of the layers, their boundaries, and their overlapping. For this purpose, generally, both non- and micro-invasive techniques, together with micro-destructive ones, are used. The non-invasive approach involves the observation of the UV-induced optical emission of the whole object surface to assess the distribution of the heterogeneities, the worn-out areas, and the retouches [9], in combination with spectroscopic techniques, as Fourier transform infrared (FTIR) spectroscopy in reflection mode [10] and X-ray fluorescence (XRF) spectroscopy [11]. Recently, non-invasive assessment of the inner layers has been achieved [12] by combining different techniques as optical coherence tomography (OCT), mobile nuclear magnetic resonance analysis (NMR-MOUSE) [13, 14], laser-induced breakdown spectroscopy (LIBS) [15] and micro-computed tomography (CT), also by exploiting synchrotron facilities [16]. Despite it, only the study of microscopic cross sections taken from musical instruments, when feasible, can provide exhaustive and incomparable information on the complex stratigraphy of the wood finish of these precious objects. For this purpose, micro-FTIR spectroscopy and SEM-EDX are generally employed for the characterization of the organic and inorganic fraction, respectively, while the optical emission from the stratigraphic sample is only qualitatively observed with the aid of UV-induced micro-photography [5, 17-19].

Over the last decades, steady-state and time-resolved photoluminescence (PL) spectroscopy has been successfully used in the cultural heritage field to characterize the emission of different luminescent materials both in the laboratory and on-site with the aid of portable instruments [20-25]. The effectiveness of the technique was proven for the identification of semiconductor-based pigments thanks to the specific PL spectral features of these materials [26-30]. When considering organic materials, the chemical specificity of the technique is lowered by the presence of multiple emitting species that give rise to broadband and less specific emission spectrum $[31,32]$. Despite it, many studies have demonstrated that the tiny spectral differences that may arise from chemical modifications or diversity in molecular properties, although not being analytical, can provide useful information [33-35]. For example, the cross-sectional study of the wood finish of historical instruments has been successfully assessed with synchrotron-based photoluminescence micro-imaging coupled with multispectral detection [36-38] and with two-photon fluorescence in combination with other non-linear microscopies [39-42]. 
In this paper, we propose to study microscopy cross-sections from historical musical instruments by coupling hyperspectral PL imaging to FTIR-ATR mapping analysis. We believe that the assessment of the optical emission from samples with a hyperspectral imaging approach (in the following quoted as micro-HSI) can thoroughly overcome the limits of UVinduced micro-photography by (i) providing highly resolved emission spectra detected in each pixel of the sample and (ii) offering the opportunity to manipulate hyperspectral data with multivariate analysis.

While hyperspectral imaging is a rapid emerging method in the Cultural Heritage field [25, 43-45], up to our knowledge its use for the investigation of the wood musical instruments finish is quite new and far from the routine. Moreover, in the Cultural Heritage field, hyperspectral imaging is often employed to detect and study light diffusely reflected by an artistic surface or sample, while it is less commonly applied to PL measurements. Finally, the use of a custom-made HSI micro-imaging camera adds a pioneering glance to the research.

The method was tested on a properly reproduced laboratory mock-up and three crosssectional samples from violins made by Lorenzo Storioni at the end of the eighteenth century in Cremona (Italy).

As a whole, the present research is aimed at: (i) proposing a micro-invasive methodological approach that improves the commonly used one to fully characterize the multi-layered coating system of bowed string musical instruments; (ii) assessing the potentiality of the innovative micro-HSI system for the investigation of these peculiar microscopic samples; (iii) collecting information around the wood finish of the Cremonese Master Storioni instruments.

\section{Materials and methods}

\subsection{Laboratory mock-up}

To set up the methodology, a mock-up simulating the coating system of bowed string musical instruments was prepared according to some documented historical recipes [46, 47]. The mock-up MU_1 (in Fig. 2) was made up of a maple wood slab (Acer pseudoplatanus L., 1753; $5 \times 5 \times 1 \mathrm{~cm}$ ) (A) sealed with a double application of ammonium caseinate (B) and coated with a layer of a linseed oil-colophony varnish layer (C) mixed with madder lake. The $15 \%$ of casein concentration (Kremer Pigmente, Aichstetten, Germany, cod. 63200) in deionized water mixed with ammonia ( $30 \%$ solution, $1 \mathrm{~mL}$ in $50 \mathrm{~g}$ of casein and water) was applied. The linseed oil-colophony varnish was prepared by mixing 75:25 linseed oil (Kremer Pigmente, cod. 73054) and colophony (Kremer Pigmente, cod. 60,300), as documented in the literature [48]. Madder lake pigment was purchased as a commercial pigment (handmade madder lake, Fantuzzi Colori Vegetali) and dispersed in the varnish layer in $20 \%$ of concentration. All the layers were manually applied by brush in two superimposed coats. A sub-millimetric sample detached from the mock-up through a scalpel was embedded in epoxy resin (Epofix Struers and Epofix Hardener with ratio 15:2) and cut in cross-sections. The surface was then dry-polished with silicon carbide fine sandpaper (1200-8000 mesh).

\subsection{Cross-sections from historical violins}

As case studies, a set of three sub-millimetric samples were collected from three different bowed string instruments made by Lorenzo Storioni (Cremona, 1744-1816): two different private owner instruments, a small violin (SL790) and a viola (SL790.1), made both in 1790, and the Bracco 1793 small violin (SL793). The micro-samples were collected under high 
magnification with a scalpel on selected areas of the musical instruments (as described by the instrument part in Fig. SI1 in Online Resource), embedded into epoxy resin (Epofix Struers and Epofix Hardener, 15:2), and then cut as cross-sections. The surface was dry-polished with silicon carbide fine sandpaper, as for the mock-up. The whole set of micro-samples selected as case studies is described in Fig. SI1 in Online Resource.

\subsection{Conventional microscopy observation under UV light}

The cross-sectioned polished samples were observed through a commercial Optical Microscope (OM) (Leica DM4000 RE, Germany), equipped with a UV lamp and a color digital camera (NIKON D750, Tokyo, Japan).

\subsection{Micro-HSI PL imaging}

Hyperspectral PL micro-imaging was performed employing a custom-made epifluorescence microscope (see [22]) coupled with a hyperspectral camera based on the Fourier transform approach. The microscope was equipped with a $50 \times$ objective (PL FLUOTAR L 50x/0.55, Leica, Wetzlar, Germany) and a dichroic mirror (Semrock, Brightline FF389-Di01, Rochester, NY, USA), allowing the analysis of a field of view of $205 \times 250 \mu \mathrm{m}^{2}$, with a spatial sampling pitch of $0.2 \mu \mathrm{m}$. The hyperspectral camera was composed of a common path birefringent interferometer (the Translating-Wedge-Based Identical Pulses eNcoding System (TWINS) $[49,50])$ combined with a cooled monochrome camera (Retiga R6, QImaging, Teledyne Photometrics, Tucson, AZ, USA, spectral range 300-1000 nm); the interferometer supplied high-quality interferograms which provided high-quality spectral images of the PL emission by Fourier transform $[51,52]$. The spectral resolution of the hyperspectral camera was set by the maximum scan delay introduced by the interferometer and could be as good as $4 \mathrm{~nm}$ at $600 \mathrm{~nm}$ wavelength. The PL was excited by a compact continuous-wave laser (DL-375-015, CrystaLaser, Reno, NV, USA) emitting at $375 \mathrm{~nm}$ and an average power density on a sample surface of $4 \mathrm{~mW} / \mathrm{mm}^{2}$.

From the hyperspectral datacube, it was possible to extract a variety of information: the direct RGB representation of the optical emission enabled the identification of different stratigraphic layers. To better discriminate the distribution of the different layers, a supervised classification algorithm — the spectral angle mapper (SAM) — was applied. It has been demonstrated in many other similar contexts that the application of this method is suitable to highlight the distribution of fluorescent substances [53-57]. The algorithm treats the spectra as vectors and determines the spectral similarity by calculating the angle between them [58]. Pixels with similar emission spectra are grouped and displayed in a grayscale, with white representing the minimum and black maximum angle, after setting a proper threshold angle value. The obtained different maps were combined in a false-color representation to visualize the distribution of the layers.

\section{$2.5 \mu$ ATR-FTIR analysis}

Analysis was performed with a Thermo Scientific Nicolet iN10 MX Infrared Microscope (Thermo Fisher Scientific, Waltham, MA, USA) mounting a slide-on ATR objective equipped with a conical germanium crystal. Infrared absorption spectra were gathered in the range $4000-675 \mathrm{~cm}^{-1}$ at a spectral resolution of $4 \mathrm{~cm}^{-1}$; the reference and background spectra were collected in the air before each map acquisition. 
The FTIR maps were acquired at low pressure and choosing a reduced slit. It avoided the crack of the brittle sample and to select the investigated layer's thickness. An aperture of $15 \times 15 \mu \mathrm{m}$, scanned in the $\mathrm{x}-\mathrm{y}$ directions with a step of $15 \mu \mathrm{m}$, was employed to map the area of interest for each sample: $45 \times 135 \mu \mathrm{m}^{2}$ (40 spectra total) for MU_1 mock-up, $75 \times$ $210 \mu \mathrm{m}^{2}$ (90 spectra) for SL790.1, $60 \times 180 \mu \mathrm{m}^{2}$ (65 spectra) for SL790 and $105 \times 210 \mu \mathrm{m}^{2}$ (112 spectra) for SL793.

Datasets were then processed with Thermo Scientific OMNIC Specta and OMNIC Picta (Thermo Fisher Scientific, Waltham, MA, USA) software. As an automatic procedure performed mapping, the obtained spectra mirror the features of the layering, in which boundaries were not sharp and different components may form each layer. Smoothing pre-treatment (Savitzky-Golay, 13 wavelengths gap size and second polynomial order) was applied to IR spectra. FTIR univariate chemical maps were produced considering the characteristic absorption bands for each identified material. The spatial distribution of the materials was displayed by a chromatic scale ranging from red for the highest to blue for the lowest values.

\subsection{SEM-EDX analysis}

The embedded micro-samples were observed at higher magnifications through an FE-SEM Tescan Mira 3XMU-series (Brno, Czech Republic) scanning electron microscope (SEM) in back-scattered electron (BSE) mode with an EDAX Apollo XL Silicon Drift Detector, setting the accelerating voltage to $20 \mathrm{kV}$ in low vacuum (100 Pa nitrogen pressure) without metallization of the sample. Elemental microanalyses were carried out directly on the polished surface. When diagnostic bands of the main inorganic functional groups were detected through FTIR spectroscopy, the characterization was deepened with the SEM-EDX investigation.

\subsection{Protocol}

The whole protocol is schematically represented in Fig. 1 and is organized in three sequential main blocks:

1. Preparation of sub-millimetric samples, as reported in Sects. 2.1 and 2.2.

2. Assessing of the layering: the microscopic observation of the cross-sections under visible and UV light provides a first essential qualitative description; the quantitative assessment of the fluorescence emission properties is then achieved through Micro-HSI PL imaging on a selected region of interest with the aim of precisely identifying the morphology of the different layers within the stratigraphy.

3. Chemical characterization: this is performed by combining $\mu$ FTIR-ATR mapping and SEM-EDX analysis when feasible. It completes the layering identification previously limited to the sole spatial distribution information, also enabling the discussion of the micro-HSI results with an insight to the chemical nature of the layers.

\section{Results}

\subsection{Laboratory mock-up}

The layering of the cross-sectional sample MU_1 can be barely detected by its observation under UV light microscopy mainly highlighting the presence of a varnish layer in which the red particles of madder lake are spread (Fig. 2). 


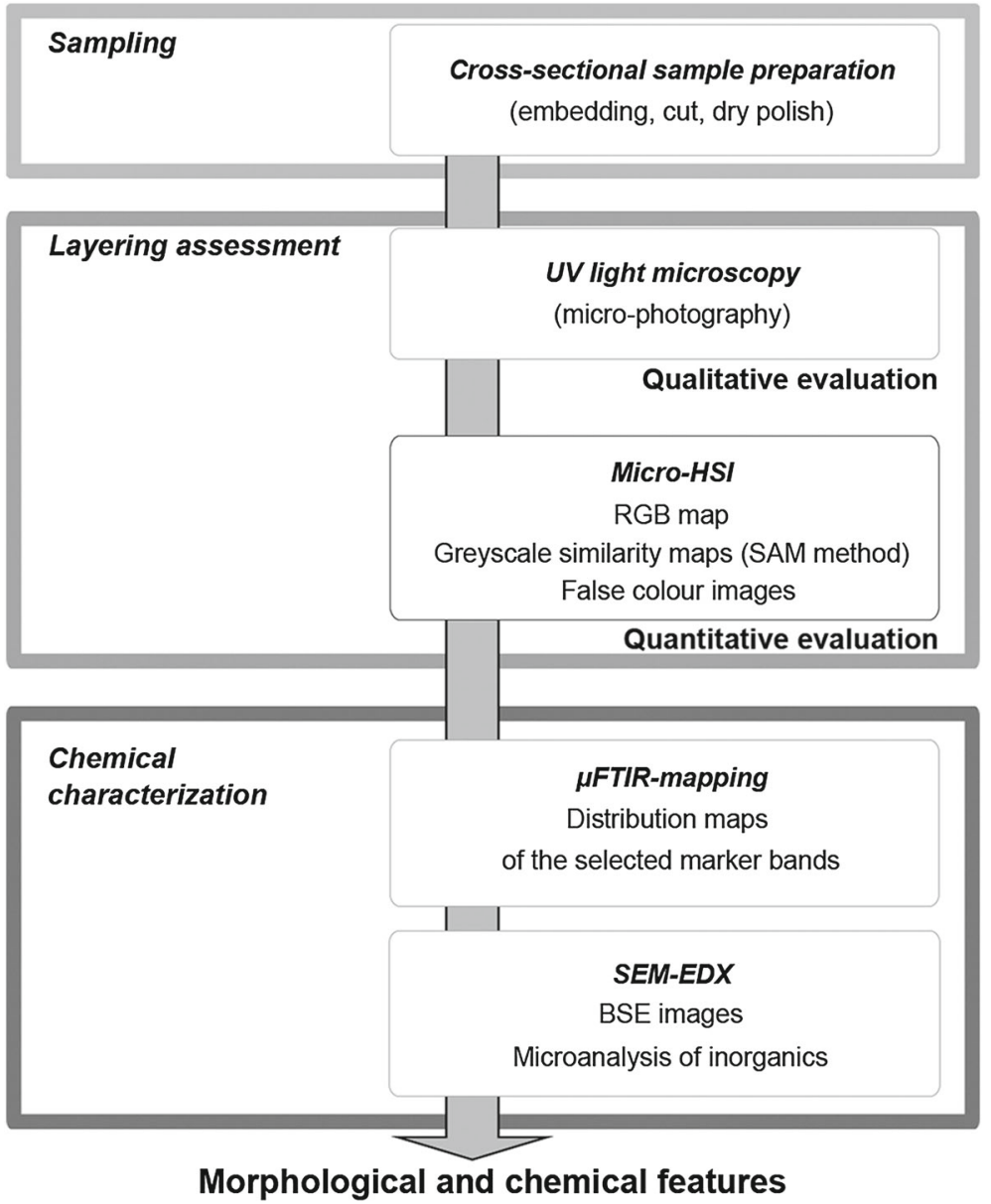

Fig. 1 Protocol scheme

In Fig. 3, the information extracted by the micro-HSI analysis is provided in terms of a reconstructed RGB image of the optical emission and mean emission spectrum in each layer of the mock-up (Fig. 3a and b). The emission of the wood (in cyan, A), of the sizing treatment (in blue, B), of the varnish (in green, C) and madder lake grains (in red, D) are all broadband and almost overlapped, apart for the spectrum of lake grains, bathochromically shifted with a maximum at $600 \mathrm{~nm}$ and a shoulder around $520 \mathrm{~nm}$ (Fig. 3b). The SAM maps reconstructed by taking as the reference spectrum the average one in an ROI of the sizing, the varnish, and the madder lake grains, respectively, are displayed in Fig. 3c, together with a false-color image generated through their combination (Fig. 3d). The SAM data processing highly enhances the modest differences among the emission spectra of the different layers. It allows us to visualize their spatial distribution with a micrometric spatial resolution. Here, the method is particularly effective for detecting the sizing and visualizing its penetration into the wood for up a couple of tens of microns proving its impregnant action. The overlapping between layer B (sizing) and A (wood which correspond to the lower part of the panels reported in Fig. 3c) confirm it. In particular, the diverse nature of layer B can be clearly evidenced: differently 


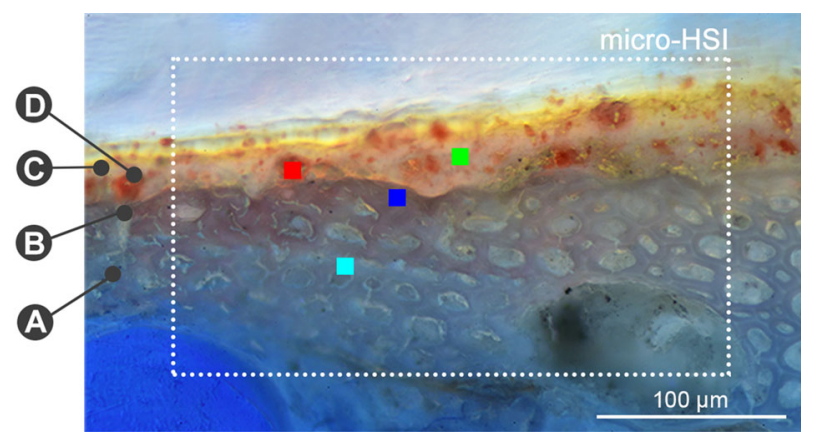

Fig. 2 MU_1 cross-section observed through OM under UV light. The capital letters mark the sample layers from bottom to top: wood (A), sizing (B), oil-based varnish (C), madder lake grains (D). The white dashed square outlines the area analyzed by micro-HSI. Colored squares mark the areas used as references for the SAM processing of micro-HSI data

by the varnish layer which properly form a film on the top of the cross-section (green area in Fig. 3d), that proteinaceous treatment (green area in Fig. 3d) can penetrate the porous wood to fulfil its task namely turning the wood in a hydrophobic suitable surface for the following application.

The univariate approach to the $\mu$ FTIR-ATR mapping dataset allows us to infer the chemical composition of the layers in the mock-up. In Fig. 4a, we report the abundance maps of selected FTIR bands, representative of each material: the peak at $1025 \mathrm{~cm}^{-1}$ related to the $\mathrm{C}-\mathrm{O}$ stretching vibration of cellulose and hemicellulose for the wood (layer A), the band of $\mathrm{vC}=\mathrm{O}$ around $1710 \mathrm{~cm}^{-1}$ for the oil-based varnish (layer $\mathrm{B}$ ), the peak related to $\mathrm{vC}=\mathrm{O}$ of the amide I at $1650 \mathrm{~cm}^{-1}$ for the protein-based material in the sizing (layer C) [59]. The spatial distribution of the peak at $1510 \mathrm{~cm}^{-1}$ attributed to $\mathrm{vC}-\mathrm{C}$ aromatic ring is also reported for the embedding resin [19]. In Fig. 4b, the spectra collected in the correspondence of each layer are shown. We note here that, based on $\mu$ FTIR-ATR data only, it is not possible to detect the presence of madder lake, probably because of the weakness of its infrared signal when present in a mixture [47].

\subsection{Cross-sections from historical violins}

\subsubsection{SL790 sample}

The image under UV light of the SL790 is displayed in Fig. 5. From bottom to top, the sample appears composed of the wood (A), the sizing (B) and a thick varnish layer (C).

Besides the detection of the wood, sizing and varnish, the analysis of micro-HSI data allows us to clearly infer the presence of an additional layer at the top of the varnish layer (labelled as D) whose presence is only slightly noticeable by the image under UV light (Fig. 5). This layer is well evidenced by the false-color composite image (Fig. 6a) reconstructed by combining different similarity maps (shown in Fig. SI2 in Online Resource) obtained based on four ROIs within the sample stratigraphy (see Fig. 5 for reference points). Apart from the modest differences between the normalized PL emission spectra of layer C (green in Fig. 6b) and $\mathrm{D}$ (orange in Fig. $6 \mathrm{~b}$ ) which alone represents a quantitative and unquestionable marker of the difference between the two layers emission properties, the combination of the highly resolved HSI data with the SAM data processing method allows us to definitely highlight the presence and the distribution of layer D. The quantitative approach of the PL and the 
(a)

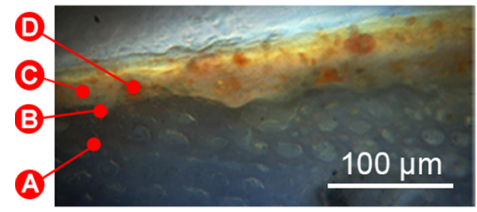

(c)
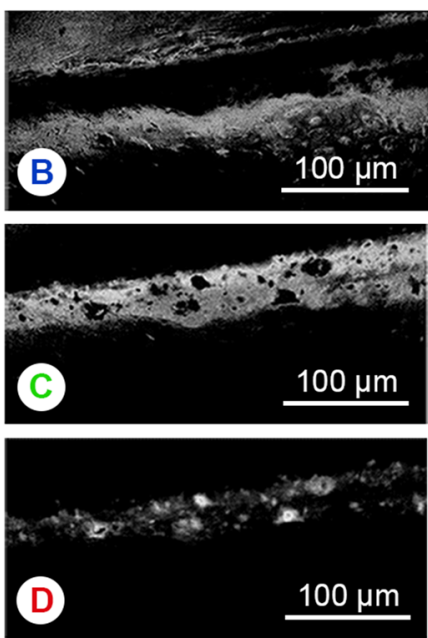

(b)

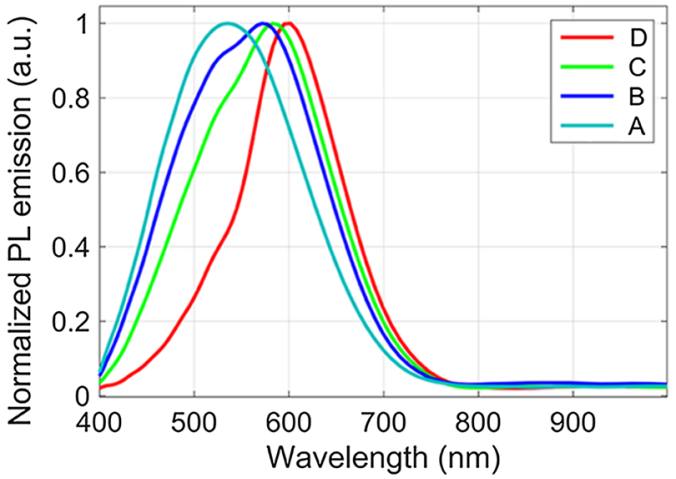

(d)

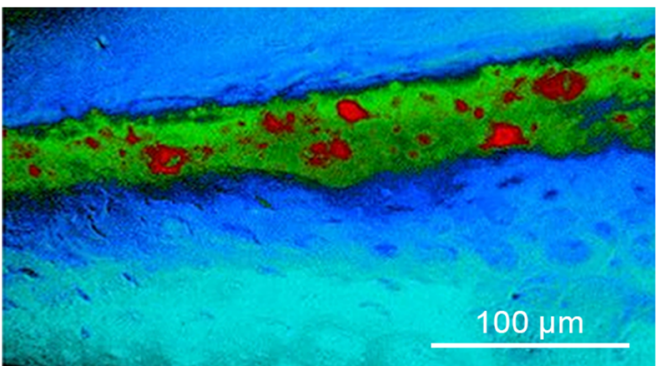

Fig. 3 Micro-HSI results on sample MU_1. a Reconstructed RGB image of the optical emission; b Mean PL emission spectra of the wood (A), the sizing (B), varnish (C), and the madder lake grains (D) — spectra are reported following normalization to the emission peak; c Similarity maps reconstructed based on the SAM algorithm by considering as reference spectra the mean one in correspondence of the sizing (B), the varnish (C), and madder lake grains (D) — angle values range between 0-7, 0-9 and 0-22 degrees, respectively; d False-color image generated by the combination of the SAM maps reported in c-the sizing is reported in blue, the varnish in green and the madder lake grains in red

(a)

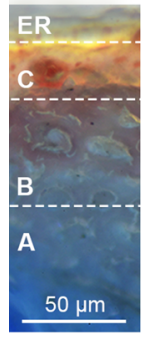

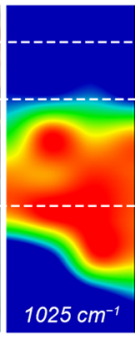

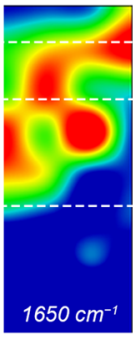

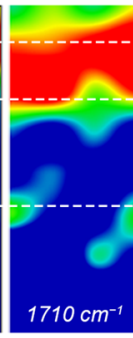

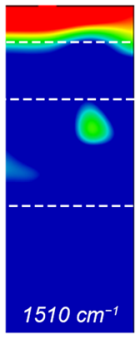

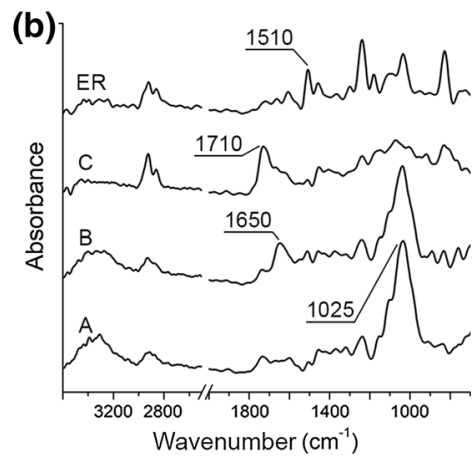

Fig. 4 a $\mu$ FTIR-ATR chemical maps and b related spectra collected on the wood (A), proteinaceous preparation (B), oil-resin varnish $(\mathrm{C})$ and on the epoxy resin (ER). The marker bands selected to highlight the distribution of each class of material are displayed 


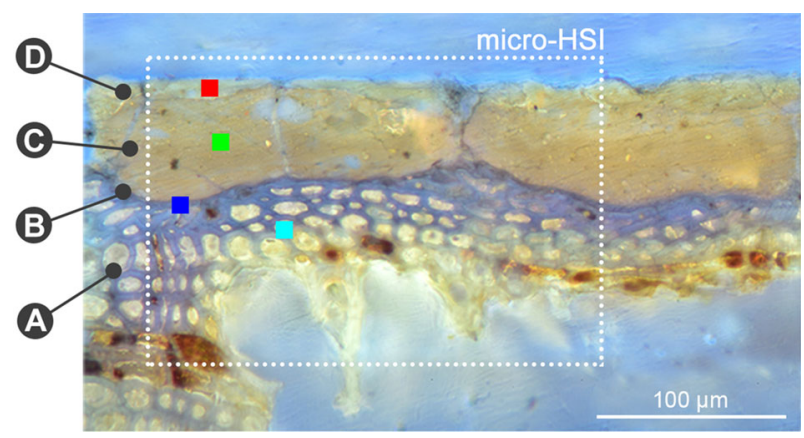

Fig. 5 SL790 cross-section observed through OM under UV light. The capital letters mark the layers from the bottom to the top: wood (A), sizing (B), varnish (C), uppermost area of the varnish layer (D). The white dashed square outlines the area of the micro-HSI analysis, the colored squares mark the sampling areas of the emission spectra used as references for the SAM processing

(a)
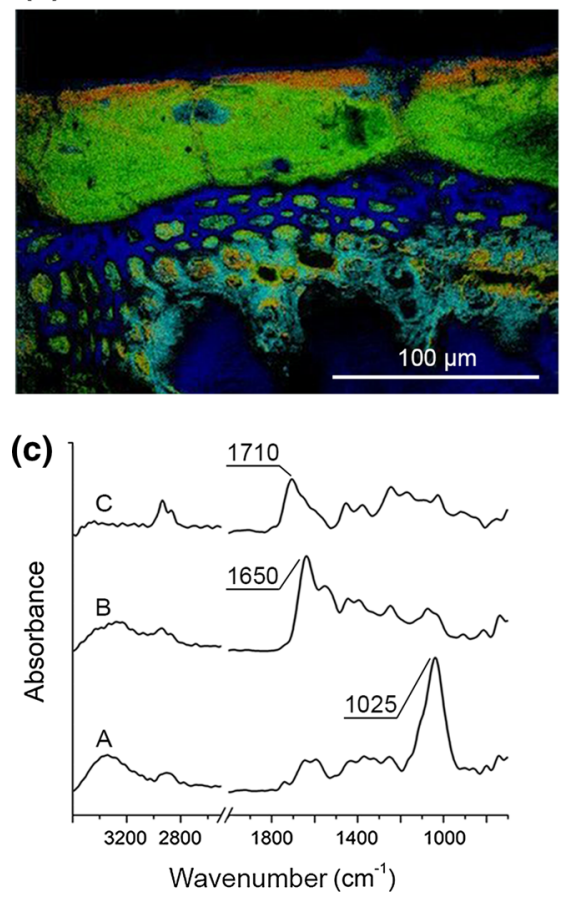

(b)

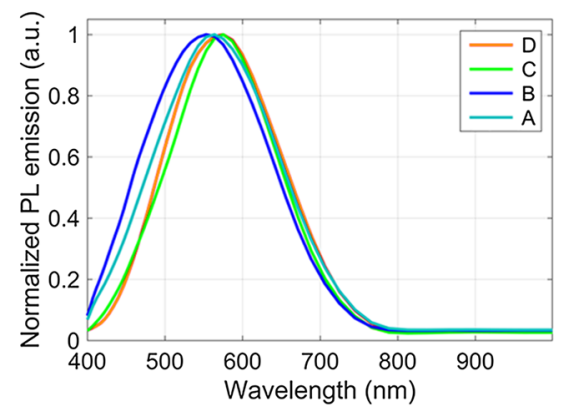

(d)
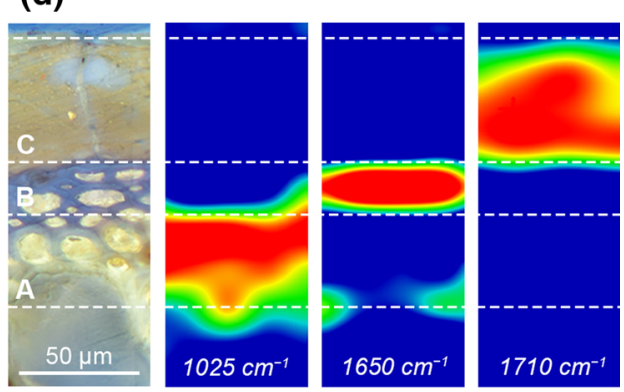

Fig. 6 a False-color image obtained by combining SAM maps collected on the SL790 (see Fig. SI2 in Online Resource); b mean PL emission spectra collected for the wood (A), the sizing (B), the varnish (C) and the additional layer on the top (D), normalized with respect to the maximum intensity; $\mathrm{c} \mu$ FTIR-ATR spectra and d related chemical maps collected on the wood (A), proteinaceous preparation (B), and oil-resin varnish (C). The marker bands selected to highlight the distribution of each class of material are displayed

data manipulation offered by the highly resolved HSI finally represent an improvement of the outcomes from the UV light image (Fig. 5).

$\mu$ FTIR-ATR data allows us to achieve the material composition of each layer (Fig. 6c). Upon the wood (A), the sizing layer (B) is well represented by the spatial distribution of the 
absorption bands at $1650 \mathrm{~cm}^{-1}\left(\mathrm{vC}=\mathrm{O}\right.$, amide $\mathrm{I}$ ) and $1550 \mathrm{~cm}^{-1}$ (a combination of $\mathrm{vC}-\mathrm{N}$ and $\delta \mathrm{N}-\mathrm{H}$, amide II) related to the proteinaceous, whereas the varnish layer $(\mathrm{C})$ is well represented by the spatial distribution of the $\mathrm{vC}=\mathrm{O}$ band around $1710 \mathrm{~cm}^{-1}$ ascribed to the natural resins. The characterization of the varnish is also completed by the presence of $\mathrm{vCH}_{2}$ and $\mathrm{vCH}_{3}$ bands due to the resins' contribution in the range $3000-2800 \mathrm{~cm}^{-1}$ with the related bending between $1450 \mathrm{~cm}^{-1}$ and $1375 \mathrm{~cm}^{-1}$ and the signals related to $\mathrm{VC}-\mathrm{O}$ at 1255 and $1185 \mathrm{~cm}^{-1}$ [59]. The sizing layer represented by the blue area in Fig. 6a goes through the wood for about $20 \mu \mathrm{m}$ depth and is identified by the $1650 \mathrm{~cm}^{-1}$ ( $\mathrm{vC}=\mathrm{O}$, amide I) band distribution (Fig. 6d). In contrast, the uppermost area of the varnish layer, highlighted by HSI imaging, does not present any specific bands at the $\mu$ FTIR-ATR analysis. This uppermost layer, more exposed to the weathering, differs from the innermost. It is probably due to the physical and chemical features modifications that occurred in the varnish upon aging: a widely explored issue in the literature $[34,60,61]$. The impossibility to detect such a change with the FTIR analysis can be explained by the low sensitivity or the scarce spatial resolution of the FTIR equipment. Also, an alteration of the sole state of matter like the roughness or the density could be no appreciable.

No signals ascribable to inorganic fraction were detected. Notwithstanding the inability of $\mu$ FTIR-ATR to chemically discriminate the uppermost layer identified by the micro-HSI, the maps (Fig. 6d) properly describe the rest of the layering according to the other results.

\subsubsection{SL790.1 sample}

In sample SL790.1, the wood and the ground layers are missing. The microscope observation under UV light revealed the presence of at least four layers (Fig. 7), two of which are highly fluorescent: A, characterized by heterogeneities of variable size and $\mathrm{C}$, described by a more compact structure in which tiny heterogeneities are spread. The difference between the two layers which is recognizable in the UV image can be better visualized through the similarity maps shown in Fig. 8a, whose spectral emission slightly differs in the broad band with a maximum around $580 \mathrm{~nm}$ (Fig. 8b). The outcome of the PL analysis provides the emission spectra of the layers, therefore quantitatively validating the different optical properties of the layers. Moreover, the multivariate approach to the hypercube of data permits a straightforward visualization of that small differences also affording the identification of small details like the particles dispersed in the layers (characterized by a different emission properties) which are much more distinguishable in the SAM (Fig. 8a) than in the UV image (Fig. 7).

The $\mu$ FTIR maps (Fig. $8 \mathrm{c}$ ) reveal the chemical feature of the layering: the spatial distribution of the varnish, highlighted through the $\mathrm{vC}=\mathrm{O}$ band centered at $1710 \mathrm{~cm}^{-1}$ (whose characterization is also completed by the presence of $\mathrm{vCH}_{2}$ and $\mathrm{vCH}_{3}$ bands in the range $3000-2800 \mathrm{~cm}^{-1}$ with the related bending between 1450 and $1350 \mathrm{~cm}^{-1}$ and the signals related to $\mathrm{vC}-\mathrm{O}$ at 1255 and $1185 \mathrm{~cm}^{-1}$ ) well describes the areas in correspondence of layer $\mathrm{A}$ and $\mathrm{C}$ and partially of layer B; whereas the distribution of the peaks at $1650 \mathrm{~cm}^{-1}$ ( $\mathrm{vC}=\mathrm{O}$, amide I) — combined with the $1550 \mathrm{~cm}^{-1}$ (combination of $\mathrm{vC}-\mathrm{N}$ and $\delta \mathrm{N}-\mathrm{H}$, amide II) - is mainly descriptive of the uppermost Layer D [59]. The spectra collected in the layer B and D areas (Fig. SI3 in Online Resource) are characterized by a strong absorbance attributable to the inorganic fraction, in particular to the characteristic band of the silicates $\mathrm{vSi}-\mathrm{O}$ around $1020 \mathrm{~cm}^{-1}$ and other absorption band related to the $\mathrm{v}+\delta \mathrm{Si}-\mathrm{O}$ falling in the range $850-700 \mathrm{~cm}^{-1}$, probably ascribable to a mixture of kaolinite, quartz and K-feldspars [62]. The investigation by SEM-EDX analyses performed on the particles revealed the signals of $\mathrm{Si}, \mathrm{Al}, \mathrm{Mg}$ and lower counts of $\mathrm{Fe}, \mathrm{K}, \mathrm{Cl}$ and $\mathrm{Ca}$ : these elements confirm the presence of silicates, probably iron-aluminosilicates and feldspars [63]. In layer B, some particles with 


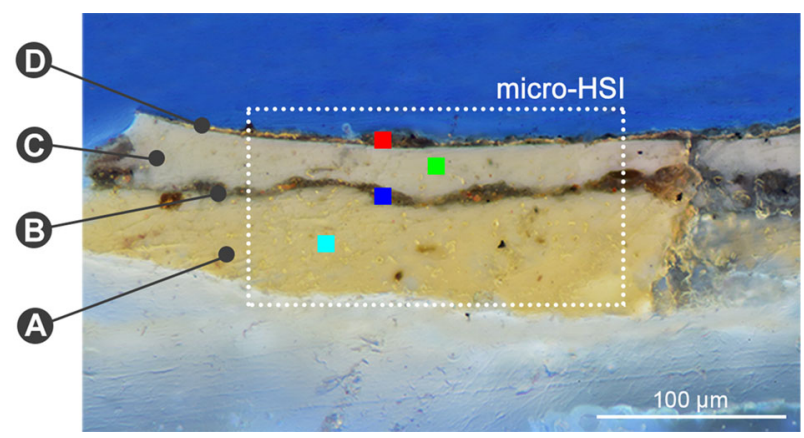

Fig. 7 SL790.1 cross-section observed through OM under UV light. The capital letters mark the layers from the bottom to the top: varnish (A), weakly fluorescent layer (B), varnish (C), weakly fluorescent layer (D). The white dashed square outlines the area of the micro-HSI analysis, the colored squares mark the sampling areas of the emission spectra used as references for the SAM processing

(a)
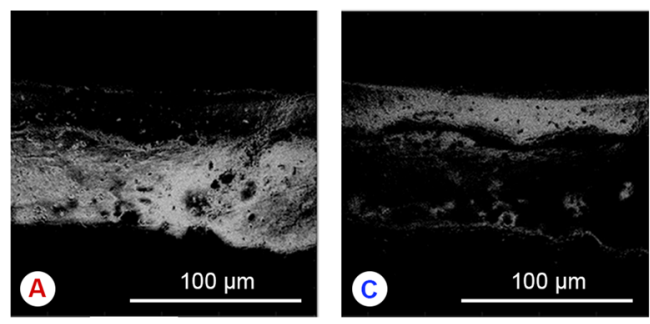

(c)
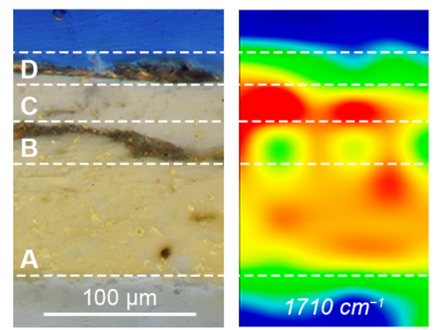

(b)

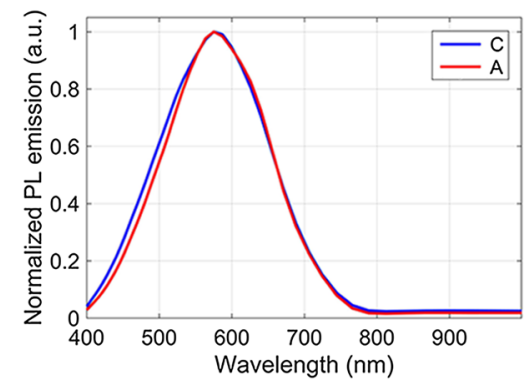

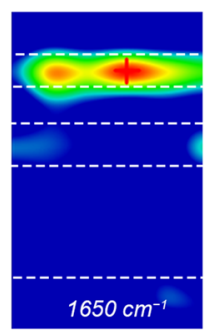

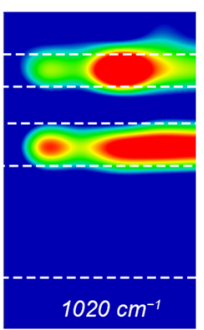

Fig. 8 a Similarity maps of SL790 sample obtained from the processing of the emission spectra of layers A (red) and C (blue); angles range from 0-4 and 0-3 degrees, respectively; b average emission spectra of the two varnish layers $A$ and $C$, spectra are shown following normalization to emission maxima; $\mathbf{c} \mu$ FTIR-ATR chemical maps

high counts of $\mathrm{Pb}$ are also detected. Silicates and carbonates, characteristics for both the dark layers, are mixed differently: with a resinous-based material in B and with a proteinaceous D.

Under this scenario, layer B, C and D are probably restoration layers superimposed to an original one (layer A). Indeed, the uppermost layer of a violin wood finish should be a transparent varnish-based layer able to give protection and shine to the instrument surface, and multiple layers made of glues and mineral mixtures are inappropriate for the purpose. The two varnish-based layers (A and C) show slight distinct emission properties and morphologies. 


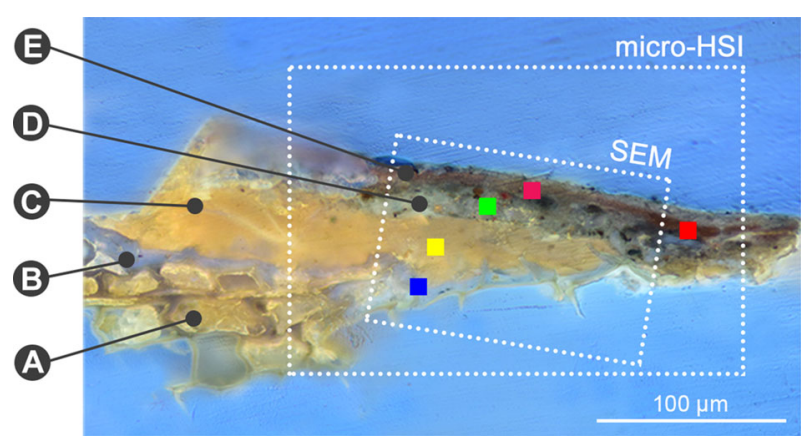

Fig. 9 SL793 cross-section observed through OM under UV light. The capital letters mark the layers from the bottom to the top: wood (A), ground coat (B), oil-based varnish (C), gray fluorescent material with dark non-fluorescent and reddish particles (D), not well defined and discontinuously brown and gray areas (E). The white dashed square outlines the area of the micro-HSI analysis, the colored squares mark the sampling areas of the emission spectra used as references for the SAM processing

Notwithstanding $\mu$ FTIR-ATR analysis points out a common chemical nature that can be explained by the unsuitable sensitivity or spatial resolution of the FTIR equipment or with a modification of the properties due to different aging degrees [33].

\subsubsection{SL793 sample}

The SL793 cross-sectional sample from the Bracco 1793 small violin displays a complex stratigraphy in which at least five layers can be recognized under UV light microscopy (Fig. 9).

The false-color composite image (Fig. 10a), made up of 5 similarity maps (Fig. SI4 in Online Resource), allows the detection of an additional layer: areas in Layer E are distinguished as two separate uppermost thin layers, the magenta-red $\left(\mathrm{E}_{1}\right)$ and the green one $\left(\mathrm{E}_{2}\right)$. Moreover, it leads to a clear definition of layer B corresponding to the sizing (green) between the wood (blue) and layer C (in yellow).

$\mu$ FTIR-ATR mapping results combined with those obtained with SEM-EDX (Fig. 10b, c), disclosed the composition of the layers. The spatial distribution of the intense $\mathrm{vC}=\mathrm{O}$ band around $1710 \mathrm{~cm}^{-1}$ — completed by the identification of $\delta \mathrm{sCH}_{2}$ and $\delta \mathrm{asCH}_{3}$ at $1450 \mathrm{~cm}^{-1}$, $\delta \mathrm{sCH}_{3}$ around $1375 \mathrm{~cm}^{-1}$, and $\mathrm{vC}-\mathrm{O}$ at 1255 and $1185 \mathrm{~cm}^{-1}$-can suggest the presence of resin-based varnish in layer C, D and E. Besides, the spatial distribution of the peak at $1650 \mathrm{~cm}^{-1}(\mathrm{vC}=\mathrm{O}$, amide I) proper of the proteinaceous - complemented by the presence of the band at $1550 \mathrm{~cm}^{-1}$ as a combination of $\mathrm{vC}-\mathrm{N}$ and $\delta \mathrm{N}-\mathrm{H}$, amide II-is mainly associated to the layer B, D and E areas [59]. In addition, numerous spectra in the area of the sizing and the uppermost layers ( $\mathrm{D}$ and $\mathrm{E}$ ) bear the signals of the inorganic fraction (see Fig. SI5 see Online Resource): when the band at $1390 \mathrm{~cm}^{-1}$, with a shoulder peak around $1360-1350 \mathrm{~cm}^{-1}$ is recognizable, it is ascribable to the lead white pigment $[64,65]$, and when the stretching vibration of the carbonate group $\left(v\left(\mathrm{CO}_{3}{ }^{-2}\right)\right)$ falling at $1420 \mathrm{~cm}^{-1}$ and the characteristic sharp peak at $870 \mathrm{~cm}^{-1}$ are present, they are related to the calcium carbonate $\left(\mathrm{CaCO}_{3}\right)$ [66]. The presence of overlapped peaks in the region between $1100-990 \mathrm{~cm}^{-1}$ related to the $\mathrm{Si}-\mathrm{O}$ stretching vibrational mode also suggests the presence of silicates [62]. SEM-EDX (Fig. 10b) confirms these results [63]: Ca-based particles dispersed in layer B (Fig. 10b, point 1) and Si-, Al- and Mg-based particles in layer D (Fig. 10b, points 2, 3 and 4) clearly identifies the presence of the ground layer enriched with minerals among the employed wood treatments 
(a)

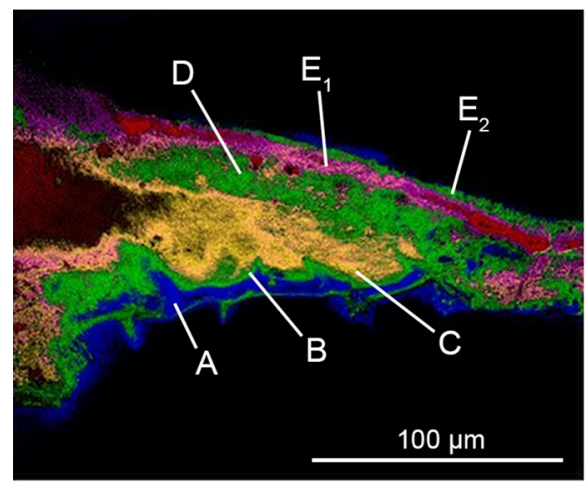

(b)

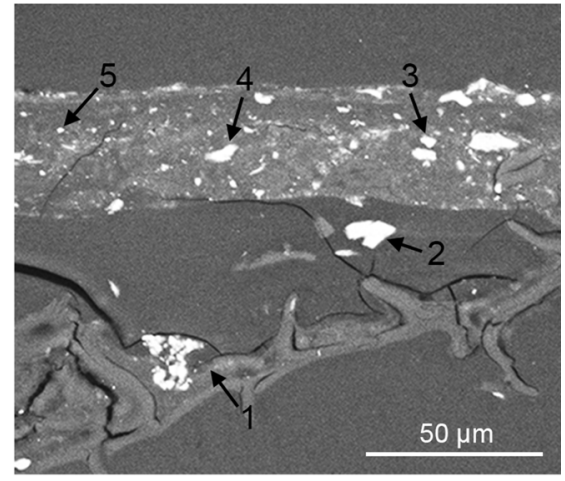

(c)
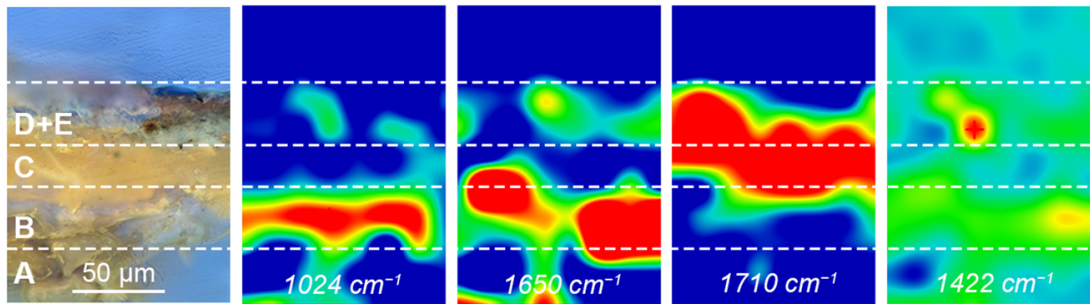

Fig. 10 SL793 investigation results: a composite image obtained by the combination of SAM maps, in which wood (blue), layer B (green), layer C (yellow), layer D (red) and layer E (uppermost magenta-red-green) are recognizable; b SEM image with EDX analytical points marked with the arrows; $\mathbf{c} \mu$ FTIR-ATR chemical maps

and inorganic particles in the proteinaceous upon the varnish. High counts of $\mathrm{Fe}$ in fine particles in layer D (Fig. 10b, point 5) also suggests the presence of iron-based pigments in the mixture.

According to the layering and its chemical feature, the presence of restoration layers can be supposed, probably those superimposed to the layer $\mathrm{C}$. The micrometric fragment was obtained by sampling from the center of the soundboard violin from a dark and restored area under the bridge. In this perspective, the presence of proteinaceous glue can be justified by following restoration actions undertaken to prevent the mechanical damage likely produced by the strain exerted by the strings in this area [67], whereas the presence of resins can be explained by the widely spread usage of the violin rosin (namely colophony) applied by the musicians on the strings and then accumulated in this area. The sequence of definite layers observed in the composite image (Fig. 10a), also supports the hypothesis of distinct events that occurred in separate moments.

\section{Discussion}

In this study, we tested for the first time the use of a hyperspectral PL imaging system. We demonstrated that extremely small differences in the optical properties of the layers can be enhanced by combining the high spectral resolution of the technique with the multivariate statistical approach. This technique does not permit the retrieval of the chemical information 
Table 1 Protocol advantages and drawbacks expressed by the high $(+++)$, medium $(++)$, low $(+)$ and lack of (-) effectiveness of each considered technique (first row) with respect to the main query (first and second column) - the stratigraphic study of musical instrument finishing is empowered by combining the techniques

\begin{tabular}{llllll}
\hline & & OM & Micro-HSI & Micro-FTIR & SEM EDX \\
\hline Morphological & Layering & ++ & +++ & + & - \\
& Wood/sizing interface & + & +++ & - & - \\
& Thin layers & + & +++ & - & - \\
& Restoration/alterations & + & +++ & - & - \\
Chemical & Organic binders & - & - & ++ & - \\
& Inorganic particles & - & - & + & ++ \\
& Madder lake & - & ++ & - & - \\
\hline
\end{tabular}

about the materials forming the layering, but it clearly displays their distribution. The chemical characterization can be achieved exploiting the vibrational properties of the molecules through the $\mu$ FTIR-ATR mapping. Binning the two techniques entails a straightforward advantage: the cross-interpretation of the results bring in a clear view of the complexity of the multi-layered system of the wood finish, also, the high spatial resolution of the hyperspectral camera can compensate for the low lateral resolution of the $\mu$ FTIR-ATR mapping, providing more accurate distribution of the layers. The results of this study (summarized in Fig. SI 2 in Online Resource) definitely put in evidence the advantages and the drawbacks of the proposed protocol (and schematically reported in Table 1) for the specific wooden artifacts. Due to the composition of the peculiar samples characterized by a mixture of organic compounds, showing broadband and partially overlapped emission properties, micro-HSI is scarcely adequate for the chemical discrimination of the material, whereas $\mu$ FTIR-ATR mapping, supported by the SEM-EDX when required, is crucial to chemically validate the layering highlighted by the processing of the hypercube of data. Among the results the detection of the madder lake is relevant. If the UV optical emission was confirmed to be exceptionally suitable and specific for its detection [68, 69], we validated the strength of the micro-HSI and the multivariate approach to enhance its signal and identification: the emission shifted toward the $600 \mathrm{~nm}$ with respect to the other classes of material commonly found in the wood finish (e.g., varnish and proteinaceous ground), precisely identify and localize the tiniest grains. Furthermore, the results highlight that the protocol works especially for the identification of the sizing layer (layer B in MU_1 and SL790) and the assessment of the penetration depth into the wood substrate. It is an outstanding result in the research field of wooden musical instruments: in fact, the sizing features are supposed to affect the vibromechanical properties of the wood and the instrument [70, 71]. This knowledge is as relevant as arduous to be achieved and the proposed non-destructive approach on cross-sections is extraordinarily advantageous to yield important information that turns to be preliminary and occasionally useful to focus the following investigation. Furthermore, by the results plenty of information have been gained about restoration processes (layers B, C and D in SL790.1; layers D and E in SL793) and ongoing transformation areas (layer C in SL790). In our knowledge, the multivariate approach to the micro-HSI data providing false-color images of the combined grayscale SAM images can be considered the best non-invasive way to achieve a precise spatial distribution of the layers and their exact boundaries, with a resolution as high as able to describe even overlapped few micrometers thin layers in a composite stratigraphy (sample SL793). 
The improvement of the micro-HSI contribution to the standard approach to the crosssectional study is evident: with the same sample preparation and spending a comparable working time, it provides quantitative information of the emission properties of each pixel supplying the compelling multivariate processing approach. Further development can lead to recommending the micro-HSI as a non-destructive screening method, with an extraordinary extended information load, if compared to the typical UV light microscopy. Moreover, the selection of a proper method for the data analysis can be crucial for a substantial upgrade of the methodology. Hence, the limits of the elected supervised classification method (SAM algorithm) represented mainly by the arbitrary choice of the reference spectrum, can be easily overwhelmed by employing an unsupervised multivariate statistical approach that must be considered for the future.

\section{Conclusions}

To conclude, we have shown the first application of a novel protocol for the cross-sectional studies of the wood finish of historical musical instruments. The methodology couples conventional micro-FTIR and SEM-EDX mapping to the accurate characterization of the UVinduced optical emission from samples through hyperspectral PL imaging.

By combining complementary mapping techniques, both morphological and chemical features of multi-layered micro-samples have been retrieved. Considering the studied samples, we showed how the method allowed us to (i) chemically identify the presence of madder lake on the basis of its PL signal; (ii) provide a high-resolution strategy to define the boundaries of thin layers, an issue that cannot be achieved by using only $\mu$ FTIR-ATR mapping, due to the low spatial resolution of the infrared technique; (iii) disclose the sizing layer features, including the sizing penetration depth into the wood; (iv) identify restoration layers and degradation areas within the varnish layer.

This application enabled us to get an insight into the historical manufacturing processes of wooden musical instruments, providing the identification of the materials employed by an important violinmaker from Cremona (Italy): Lorenzo Storioni, who is one of the last interpreters of the Cremonese tradition.

Supplementary Information The online version contains supplementary material available at https://doi. org/10.1140/epjp/s13360-021-02033-3.

Acknowledgements The authors would like to thank the Fondazione Arvedi Buschini and the Fondazione Bracco, which funded the research activities of the Arvedi Laboratory, and Prof. Claudio Canevari (University of Pavia, Department of Musicology and Cultural Heritage) for the support generously offered in the preparation of the mock-up. A special acknowledgement to $\mathrm{M}^{\circ}$ Claudio Amighetti for providing us with the samples which were objects of this study.

Authors' contributions M.A., D.C., and M.M. account for the conceptualization of the work; M.A. and G.F. selected and prepared the mock-up and the cross-sectional samples under investigation. M.G. and M.A. carried out the micro-HSI analysis and the data interpretation. C.M. developed the customized the equipment for the micro-HSI and the dataset processing. M.A. and G.F. performed the micro-invasive analysis ( $\mu$ FTIR-ATR, SEM-EDX) and data interpretation. M.M. supervised the work. M.A. wrote the manuscript draft with inputs from the other authors. All authors reviewed and approved the final manuscript.

Funding Open access funding provided by Politecnico di Milano within the CRUI-CARE Agreement.

Data availability The datasets generated during and/or analyzed during the current study are available from the corresponding author on reasonable request. 


\section{Declarations}

Conflicts of interest The author reports no conflict of interest at this time. If a conflict of interest is identified after publication, a correction will be submitted.

Open Access This article is licensed under a Creative Commons Attribution 4.0 International License, which permits use, sharing, adaptation, distribution and reproduction in any medium or format, as long as you give appropriate credit to the original author(s) and the source, provide a link to the Creative Commons licence, and indicate if changes were made. The images or other third party material in this article are included in the article's Creative Commons licence, unless indicated otherwise in a credit line to the material. If material is not included in the article's Creative Commons licence and your intended use is not permitted by statutory regulation or exceeds the permitted use, you will need to obtain permission directly from the copyright holder. To view a copy of this licence, visit http://creativecommons.org/licenses/by/4.0/.

\section{References}

1. J. Michelman, J. Franklin Inst. (1949). https://doi.org/10.1016/0016-0032(49)90411-1

2. B.H. Tai, J. Violin Soc. Am. 21(1), 119-144 (2007)

3. J.P. Echard, B. Lavédrine, J. Cult. Herit. (2008). https://doi.org/10.1016/j.culher.2008.03.005

4. J. Nagyvary, R.N. Guillemette, C.H. Spiegelman, PLoS ONE (2009). https://doi.org/10.1371/journal. pone. 0004245

5. G. Fiocco, T. Rovetta, M. Gulmini, A. Piccirillo, M. Licchelli, M. Malagodi, Appl. Spectrosc. 71, 2477-2487 (2017). https://doi.org/10.1177/0003702817715622

6. B.H. Tai, J. Violin Soc. Am. 22(1), 60-90 (2009)

7. J.P. Echard, L. Bertrand, A. Von Bohlen, A.-S. Le Hô, C. Paris, L. Bellot-Gurlet, B. Soulier, A. LattuatiDerieux, S. Thao, L. Robinet, B. Lavédrine, S. Vaiedelich, ACIEAY (2009). https://doi.org/10.1002/anie. 200905131

8. S. Zumbühl, B. Soulier, C. Zindel, J. Cult. Herit. (2020). https://doi.org/10.1016/j.culher.2020.10.001

9. P. Dondi, L. Lombardi, M. Malagodi, M. Licchelli, J. Cult. Herit. (2016). https://doi.org/10.1016/j.culher. 2016.05.010

10. C. Invernizzi, A. Daveri, T. Rovetta, M. Vagnini, M. Licchelli, F. Cacciatori, M. Malagodi, Microchem. J. (2016). https://doi.org/10.1016/j.microc.2015.10.016

11. T. Rovetta, C. Invernizzi, G. Fiocco, M. Albano, M. Licchelli, M. Gulmini, G. Alff, D. Fabbri, A.G. Rombolà, M. Malagodi, J. Archaeol. Sci. Rep. (2019). https://doi.org/10.1016/j.jasrep.2018.11.010

12. C. Invernizzi, G.V. Fichera, M. Licchelli, M. Malagodi, Microchem. J. (2018). https://doi.org/10.1016/j. microc.2018.01.021

13. C. Invernizzi, G. Fiocco, M. Iwanicka, M. Kowalska, P. Targowski, B. Blümich, C. Rehorn, V. Gabrielli, D. Bersani, M. Licchelli, M. Malagodi, Microchem. J. (2020). https://doi.org/10.1016/j.microc.2020.10 4754

14. B. Blümich, M. Baias, C. Rehorn, V. Gabrielli, D. Jaschtschuk, C. Harrison, C. Invernizzi, M. Malagodi, Microchem. J. (2020). https://doi.org/10.1016/j.microc.2020.105219

15. F. Poggialini, G. Fiocco, B. Campanella, S. Legnaioli, V. Palleschi, M. Iwanicka, P. Targowski, M. Sylwestrzak, C. Invernizzi, T. Rovetta, M. Albano, M. Malagodi, J. Cult. Herit. (2020). https://doi.org/1 0.1016/j.culher.2020.01.011

16. G. Fiocco, T. Rovetta, C. Invernizzi, M. Albano, M. Malagodi, M. Licchelli, A. Re, A.L. Giudice, G.N. Lanzafame, F. Zanini, M. Iwanicka, P. Targowski, M. Gulmini, Coatings (2019). https://doi.org/10.3390/ coatings 9020081

17. M. Malagodi, C. Canevari, L. Bonizzoni, A. Galli, F. Maspero, M. Martini, Appl. Phys. A (2013). https:// doi.org/10.1007/s00339-013-7792-2

18. S. Prati, G. Sciutto, I. Bonacini, R. Mazzeo, Top. Curr. Chem. (2016). https://doi.org/10.1007/s41061-0 16-0025-3

19. G. Fiocco, C. Invernizzi, S. Grassi, P. Davit, M. Albano, T. Rovetta, C. Stani, L. Vaccari, M. Malagodi, M. Licchelli, M. Gulmini, Spectrochim Acta A (2021). https://doi.org/10.1016/j.saa.2020.118926

20. A. Romani, C. Clementi, C. Miliani, G. Favaro, Acc. (2010). https://doi.org/10.1021/ar900291y

21. A. Mounier, S. Lazare, G. Le Bourdon, C. Aupetit, L. Servant, F. Daniel, Microchem. J. (2019). https:// doi.org/10.1016/j.microc.2016.01.008 
22. D. Comelli, A. Artesani, A. Nevin, S. Mosca, V. Gonzalez, M. Eveno, G. Valentini, Materials. (2017). https://doi.org/10.3390/ma10111335

23. M. Ghirardello, G. Valentini, L. Toniolo, R. Alberti, M. Gironda, D. Comelli, Microchem. J. (2020). https://doi.org/10.1016/j.microc.2020.104618

24. M. Ghirardello, N.M. Kelly, G. Valentini, L. Toniolo, D. Comelli, Anal. Methods (2020). https://doi.org/ 10.1039/D0AY01160F

25. M. Picollo, C. Cucci, A. Casini, L. Stefani, J. Sens. (2020). https://doi.org/10.3390/s20102843

26. E.M. Angelin, M. Ghirardello, S. Babo, M. Picollo, L. Chelazzi, M.J. Melo, A. Nevin, G. Valentini, D. Comelli, Microchem. J. (2020). https://doi.org/10.1016/j.microc.2020.105004

27. B. van Driel, A. Artesani, K.J. van den Berg, J. Dik, S. Mosca, B. Rossenaar, J. Hoekstra, A. Davies, A. Nevin, G. Valentini, D. Comelli, Dyes Pigm (2018). https://doi.org/10.1016/j.dyepig.2018.03.012

28. F. Rosi, C. Grazia, F. Gabrieli, A. Romani, M. Paolantoni, R. Vivani, B.G. Brunetti, P. Colomban, C. Miliani, Microchem. J. (2016). https://doi.org/10.1016/j.microc.2015.07.025

29. A. Artesani, S. Bellei, V. Capogrosso, A. Cesaratto, S. Mosca, A. Nevin, G. Valentini, D. Comelli, Appl. Phys. A (2016). https://doi.org/10.1007/s00339-016-0578-6

30. A. Cesaratto, C. D’Andrea, A. Nevin, G. Valentini, F. Tassone, R. Alberti, T. Frizzi, D. Comelli, Anal. Methods (2014). https://doi.org/10.1039/C3AY41585F

31. J.R. Lakowicz, Principles of Fluorescence Spectroscopy (Springer, Boston, 1999)

32. A. Nevin, D. Comelli, G. Valentini, R. Cubeddu, Anal Chem. (2009). https://doi.org/10.1021/ac8019152

33. E.R. De La Rie, Part I. Stud. Conserv. (1982). https://doi.org/10.2307/1505977

34. A. Nevin, D. Anglos, S. Cather, A. Burnstock, Appl. Phys. A. (2008). https://doi.org/10.1007/s00339-00 $8-4460-\mathrm{z}$

35. K.A. Dooley, A. Chieli, A. Romani, S. Legrand, C. Miliani, K. Janssens, J.K. Delaney, Angew Chem (2020). https://doi.org/10.1002/anie.201915490

36. M. Thoury, J.P. Echard, M. Réfrégiers, B. Berrie, A. Nevin, F. Jamme, L. Bertrand, Anal. Chem (2011). https://doi.org/10.1021/ac102986h

37. L. Bertrand, L. Robinet, S.X. Cohen, C. Sandt, A.-S.L. Hô, B. Soulier, A. Lattuati-Derieux, J.-P. Echard, Anal. Bioanal. Chem. (2011). https://doi.org/10.1007/s00216-010-4288-1

38. J.P. Echard, M. Thoury, B.H. Berrie, T. Séverin-Fabiani, A. Vichi, M. Didier, M. Réfrégiers, L. Bertrand, Analyst (2015). https://doi.org/10.1039/c5an00483g

39. G. Latour, J.-P. Echard, B. Soulier, I. Emond, S. Vaiedelich, M. Elias, Appl. Opt. (2009). https://doi.org/ 10.1364/ao.48.006485

40. G. Latour, G. Georges, L. Siozade, C. Deumié, J.-P. Echard, O3A Opt Arts Architect. Archaeol. II. (2009). https://doi.org/10.1117/12.827856

41. G. Latour, J.-P. Echard, M. Didier, M.C. Schanne-Klein, Opt. Exp. (2012). https://doi.org/10.1364/oe.2 0.024623

42. G. Latour, J.-P. Echard, M. Didier, M.-C. Schanne-Klein, Opt. Arts Architect. Archaeol. IV (2013). https:// doi.org/10.1117/12.2020221

43. C. Fischer, I. Kakoulli, Stud. Conserv. (2006). https://doi.org/10.1179/sic.2006.51.Supplement-1.3

44. H. Liang, Appl. Phys. A (2012). https://doi.org/10.1007/s00339-011-6689-1

45. C. Cucci, J.K. Delaney, M. Picollo, Acc. Chem. Res. 49, 10 (2016). https://doi.org/10.1021/acs.accounts. $6 \mathrm{~b} 00048$

46. S. Tirat, I. Degano, J.P. Echard, A. Lattuati-Derieux, A. Lluveras-Tenorio, A. Marie, S. Serfaty, J.Y. Le Huerou, Microchem. J. (2016). https://doi.org/10.1016/j.microc.2015.11.045

47. G. Fiocco, T. Rovetta, M. Gulmini, A. Piccirillo, C. Canevari, M. Licchelli, M. Malagodi, Coatings (2018). https://doi.org/10.3390/coatings8050171

48. M.L. Weththimuni, C. Canevari, A. Legnani, M. Licchelli, M. Malagodi, M. Ricca, A. Zeffiro, A. Int. J. Conserv. Sci. 7(SI2), 813-826 (2016)

49. D. Brida, C. Manzoni, G. Cerullo, CLEO Conf. Lasers Electro Opt. 3, 7 (2013). https://doi.org/10.1364/ CLEO_SI.2013.CF2G.3

50. C. A. Manzoni, D. Brida, G. Cerullo, N. F. United States Patent US 9,182,284 B2 (2015).

51. A. Perri, B.E. Nogueira de Faria, D.C. Teles Ferreira, D. Comelli, G. Valentini, F. Preda, D. Polli, A.M. de Paula, G. Cerullo, C. Manzoni, Opt. Exp. (2019). https://doi.org/10.1364/OE.27.015956

52. A. Candeo, B.E. Nogueira de Faria, M. Erreni, G. Valentini, A. Bassi, A.M.D. Paula, G. Cerullo, C. Manzoni, APL Photon. (2019). https://doi.org/10.1063/1.5129860

53. A. Pelagotti, A. Del Mastio, A. De Rosa, A. Piva, IEEE Signal Process Magaz. (2008). https://doi.org/1 0.1109/MSP.2008.923095

54. J. Van der Weerd, M.K. van Veen, R.M.A. Heeren, J.J. Boon, Anal. Chem. (2003). https://doi.org/10.10 $21 / \mathrm{ac} 020282 \mathrm{~g}$ 
55. J.K. Delaney, J.G. Zeibel, M. Thoury, R. Littleton, M. Palmer, K.M. Morales, E.R.D.L. Rie, A. Hoenigswald, Appl. Spectrosc. (2010). https://doi.org/10.1366/000370210791414443

56. D. Comelli, A. Nevin, G. Valentini, I. Osticioli, E.M. Castellucci, L. Toniolo, D. Gulotta, R. Cubeddu, J. Cult. Herit. (2011). https://doi.org/10.1016/j.culher.2010.06.003

57. E. D’Elia, P. Buscaglia, A. Piccirillo, M. Picollo, A. Casini, C. Cucci, L. Stefani, F.P. Romano, C. Caliri, M. Gulmini, Microchem. J. (2020). https://doi.org/10.1016/j.microc.2019.104541

58. F.A. Kruse, A.B. Lefkoff, J.B. Boardman, K.B. Heidebrecht, A.T. Shapiro, P.J. Barloon, A.F.H. Goetz, Remote Sens. Environ. (1993). https://doi.org/10.1016/0034-4257(93)90013-N

59. S.G. Fiocco, C. Invernizzi, T. Rovetta, M. Albano, P. Davit, M. Gulmini, C. Stani, L. Vaccari, M. Licchelli, M. Malagodi, Acta Imeko. (2021). https://doi.org/10.21014/acta_imeko.v10i1.836

60. M. F. Mecklenburg, C. S. Tumosa, D. Erhardt, MRS Online Proceed. Library Archive, p 852

61. P. Dietemann, C. Higgitt, M. Kälin, M.J. Edelmann, R. Knochenmuss, R. Zenobi, J. Cult. Herit. (2009). https://doi.org/10.1016/j.culher.2008.04.007

62. B.J. Saikia, G. Parthasarathy, J. Mod. Phys (2010). https://doi.org/10.4236/jmp.2010.14031

63. J.E. Welton, SEM Petrology Atlas (Published by The American Association of Petroleum Geologists, Tulsa, Oklahoma, 1984)

64. M.H. Brooker, S. Sunder, P. Taylor, V.J. Lopata, Can. J. Chem. (1983). https://doi.org/10.1139/v83-087

65. E. Possenti, C. Colombo, M. Realini, C.L. Song, S.G. Kazarian, Anal. Bioanal. Chem. (2020). https:// doi.org/10.1007/s00216-020-03016-6

66. F.A. Andersen, L. Brecevic, Acta Chem. Scand. (1991). https://doi.org/10.3891/acta.chem.scand.45-101 8

67. M. Fioravanti, G. Goli, B. Carlson, J. Cult. Herit. (2012). https://doi.org/10.1016/j.culher.2011.07.005

68. T. Vittorino, A. Casini, C. Cucci, M.J. Melo, M. Picollo, L. Stefani, Appl. Phys. A. (2015). https://doi. org/10.1007/s00339-015-9360-4

69. C.S. Chane, M. Thoury, A. Tournié, J.-P. Echard, Appl. Spectrosc. (2015). https://doi.org/10.1366/14-07 554

70. F. Setragno, M. Zanoni, F. Antonacci, A. Sarti, M. Malagodi, T. Rovetta, C. Invernizzi, Acta Acust. United. Ac. (2017). https://doi.org/10.3813/AAA.919035

71. S.L. Lämmlein, D. Mannes, B. Van Damme, I. Burgert, F.W. Schwarze, J. Mater. Sci. (2019). https://doi. org/10.1007/s10853-019-03440-9.s 